\title{
Design and analysis of 32 bit CMOS adder using sub-threshold voltage at deep submicron technology
}

\author{
Jaspreet Kaur ${ }^{1}$ and Parminder Singh ${ }^{2}$ \\ ${ }^{1}$ M-Tech Student, Department of Electronics, Yadavindra college of Engineering, Talwandi Sabo(Pb)-INDIA \\ ${ }^{2}$ Parminder Singh, Assistant Professor, Department of Electronics, Yadavindra College of Engineering, Talwandi Sabo
}

\begin{abstract}
FA is basic cell for arithmetic operation and lots of efforts have put to minimize power consumption and delay. This paper evaluates conventional CMOS adder, bridge style adders in sub-threshold region. Circuits are designed at $20 \mathrm{MHz}$ and $50 \mathrm{MHz}$ frequencies with $\mathrm{V}_{\mathrm{DD}}=200 \mathrm{mv}$. All adder designs are simulated at $32 \mathrm{~nm}$ technology. In 1 bit and 32 bit conventional CMOS adder design, an efficient trade-off between delay and power is achieved. Experimental results show that 32 bit adder designs have significant improvements in delay and power delay product.
\end{abstract}

\section{Introduction}

CMOS VLSI circuits has been identified as a critical technology need in the recent years due to the high demand for low power consumption, lower delay, small area and low cost design are increasing every day. In VLSI applications, arithmetic operations play an important role in modern processing systems. Major operations of arithmetic are addition, Sub-traction, multiplication and accumulation. Full adder (FA) cell is the basic block for most of arithmetic systems. Improving the FA characteristics is critical for measuring overall system quality. In many computers and other kinds of processor, adders are not used only in the arithmetic logic units, but also in other parts of the processor, where they are used to calculate addresses, table indices, and similar operation.

Sub-threshold design is a technique for reducing dissipated power [1]. Due to portable devices; the adder must have high speed, lesser area and lower power consumption. Devices like mobile, Laptops etc. require more battery backup. So, a VLSI designer has to optimize these three parameters in a design. Basically full adder is the core components of microprocessor and other complex chips. So the performance of full adder would affect the system as a whole. All the circuits are designed in sub-threshold region. The main factor in sub-threshold design is maintaining a good trade-off between power consumption and performance. In recent years, considerable research has been performed on FA design with various design methodologies and different technologies [9]. In these days several Adder designs have been proposed to reduce the power consumption. Logic minimization gives better results in power

${ }^{1}$ Jaspreetkaurp1@gmail.com consumption. For low power results it is always advisable to use CMOS technology. In paper, three different 1-bit full adder topologies in deep sub-threshold operation are proposed. The cells are characterized with respect to delay, power consumption, Power-Delay Product (PDP) and leakage power. Conventional CMOS Adder and Bridge style adders are designed at $20 \mathrm{mhz}$ and $50 \mathrm{mhz}$ frequencies with $\mathrm{V}_{\mathrm{DD}}=200 \mathrm{mv}$.

\section{Sub-threshold design}

In sub-threshold circuits, the supply voltage is reduced well below the threshold voltage. Due to reduction in power with respect to supply voltage, sub-threshold circuits are classified as ultra-low-power circuits. Specifically in application areas where performance can be sacrificed for low power, sub-threshold circuits are ideal fit [11].

Some of the applications include devices such as digital watched, radio frequency identification (REID), sensor nodes and battery operated devices such as, cellular phones.Design spectrum is a trade-off between power consumption and performance. One extreme aim of this spectrum is ultra-low power while performance is of secondary importance. In this solution, circuit is biased in sub-threshold region so that standard CMOS logic is extended to operate in sub-threshold region by reducing the supply voltage $\mathrm{V}_{\mathrm{dd}}$ less than transistor threshold voltage $V_{t}$. The motivation for using sub- $V_{t}$ circuits is the ability to exploit the sub $\mathrm{V}_{\mathrm{t}}$ leakage current as the operating drive current. In sub-threshold region, the reduction in power consumption outweighs the increase in delay. Thus the circuit has lower PDP when it operates in sub-threshold region. So in the same frequency, when 
the circuit operates in sub-threshold region, its energy consumption is less than when it works in supperthreshold.

\section{A Review on full adder circuits}

In this section, various 1-bit full Adder designs are examined. Some of these schemes are based on CMOS logic with low power consumption, good signal logic level and high driving ability.

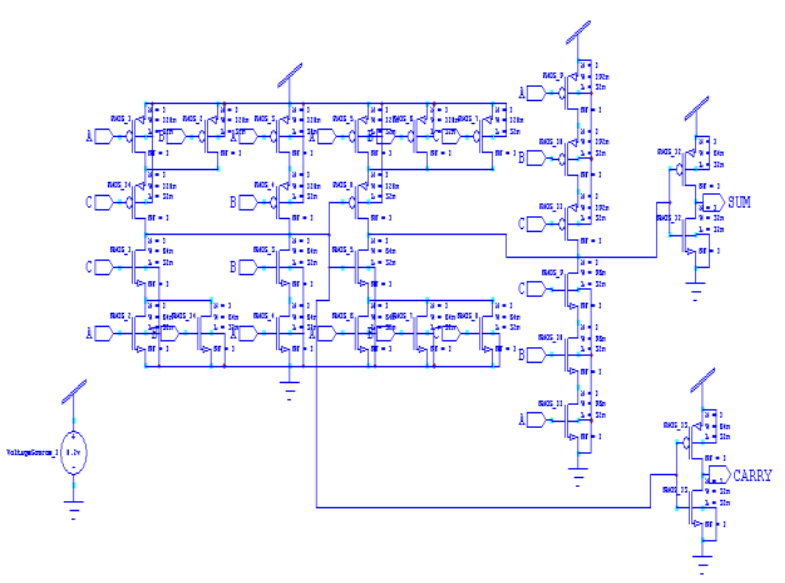

Figure 1. Conventional CMOS 1 bit full adder (CCMOS)

The schematic shown in the above fig. is CCMOS full adder [9] designed in the tanner schematic editor, which is based on regular structure CMOS logic and almost equal rise and fall time. It uses 28 transistors to complete one bit full adder. In this section bridge style 1-bit full adder introduced which operating in sub- $\mathrm{V}_{\mathrm{t}}$ region is introduced. This can be divided into two main modules: sum module and carry module. Equations (1) and (2) show the logical functions of the full adder outputs.

$$
\begin{gathered}
\text { Sum }=a \oplus b \oplus c \\
\text { Carry }=a \cdot b+b . c+a . c
\end{gathered}
$$

Based on these equations, two implementation of full adder with bridge design are investigated. The first is shown in fig. 2 which called in this paper as Bridge_v2. This design needs 24 transistors against conventional CMOS full adder uses 28 transistors and should have complementary inputs. Third design is Bridge v3 shown in fig. 3. These three circuits are designed and simulated at $32 \mathrm{~nm}$ technology. Bridge method uses some transistors, called bridge transistors, as conditional conjunction between two nodes of circuit so this method shares transistors of different paths from power supply to output.

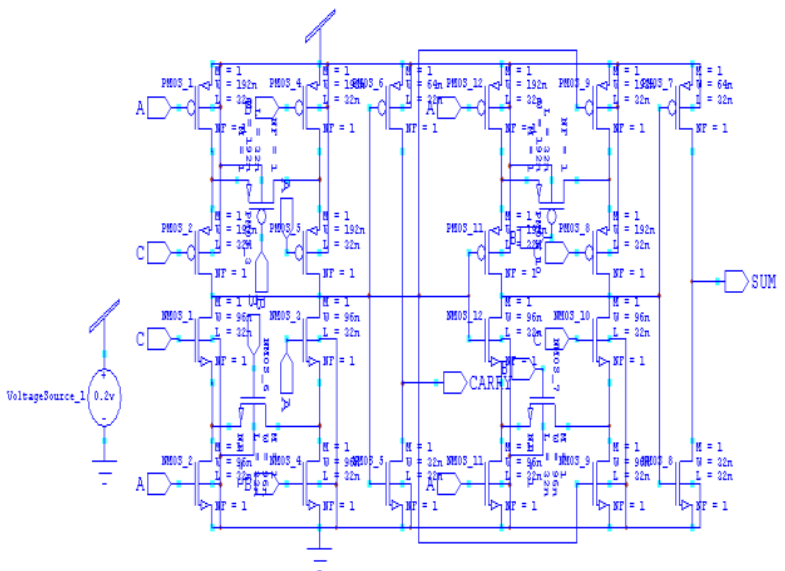

Figure 2. Bridge type (B_V2) 1 bit full adder style.

It uses 24 transistors for evaluating the sum and carry. The name itself shows that it uses bridge type structure for implementing the SUM and CARRY. It shares the path between carry and sum circuits with fully symmetric full adder structure fig 2 .

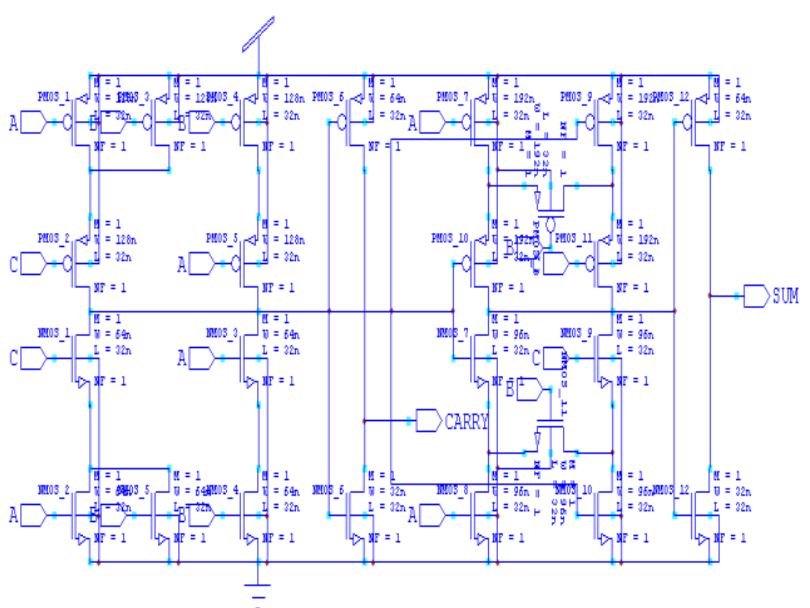

Figure 3. Bridge type (B_V3) 1 bit full adder style.

It uses 24 transistors for evaluating the sum and carry. It shares the path between carry and sum circuits with semi symmetric full adder structure fig 3 .

\section{Results}

\subsection{Results of full adder at $32 \mathrm{~nm}$}

Table 1 represent comparison results of 1 bit full adders. Proposed designs CCMOS, Bridge style are simulated at $20 \mathrm{MHz}$ and $50 \mathrm{MHz}$ frequency. In this, parameters like average power consumption, delay and power delay product are measured. Our result shows improvement in average power consumption and power delay product. 
Table 1. Result of 1 bit adders

\begin{tabular}{|c|c|c|c|c|c|c|c|c|}
\hline \multirow{2}{*}{$\begin{array}{l}\text { Sr } \\
\text { no }\end{array}$} & \multirow{2}{*}{ Parameters } & \multicolumn{2}{|c|}{$\begin{array}{c}\text { S. Wairya et.al } \\
{[6]}\end{array}$} & \multirow{2}{*}{$\begin{array}{l}\begin{array}{r}\text { Farshad } \\
\text { Moradi } \\
\text { et.al [7] }\end{array} \\
\text { CMOS }\end{array}$} & \multirow{2}{*}{$\begin{array}{c}\begin{array}{c}\text { Xu Wang } \\
\text { et.al } \\
{[8]}\end{array} \\
\text { CMOS }\end{array}$} & \multicolumn{3}{|c|}{$\begin{array}{c}\text { Proposed design } \\
{[20 \mathrm{MHz}]}\end{array}$} \\
\hline & & CCMOS & $\begin{array}{l}\text { BRIDGE } \\
\text { STYLE }\end{array}$ & & & CCMOS & $\begin{array}{c}\text { BRIDGE } \\
\text { STYLE } \\
\text { (B_V2) }\end{array}$ & $\begin{array}{c}\text { BRIDGE } \\
\text { (B_V3) } \\
\text { semi- } \\
\text { symmetric }\end{array}$ \\
\hline 1. & Technology & \multicolumn{2}{|c|}{$90 \mathrm{~nm}$} & $65 \mathrm{~nm}$ & $180 \mathrm{~nm}$ & \multicolumn{3}{|c|}{$32 \mathrm{~nm}$} \\
\hline 2. & $\begin{array}{c}\text { Average } \\
\text { power }(\mu \mathrm{w})\end{array}$ & 2.24 & 1.82 & 0.021 & 0.000049 & 0.00753 & 0.00881 & 0.00769 \\
\hline 3. & Delay (ns) & 0.524 & 0.323 & 1000 & 14 & 7.5 & 8.66 & 8.69 \\
\hline 4. & $\begin{array}{l}\text { Power delay } \\
\text { product(fj) }\end{array}$ & 1.17 & 0.59 & 21.0 & 694.4 & 0.05647 & 0.07629 & 0.06683 \\
\hline 5. & $\begin{array}{c}\text { Leakage } \\
\text { power (nw) }\end{array}$ & - & - & - & - & 2.127 & 2.422 & 2.132 \\
\hline
\end{tabular}

In table 2 all the circuit designs are simulated at $50 \mathrm{MHz}$ frequency. In this, parameters like average power consumption, delay and power delay product and leakage power are measured.

Table 2. Result of 1 bit adders at $\mathrm{f}=50 \mathrm{MHz}$

\begin{tabular}{|c|c|c|c|c|c|c|c|}
\hline Sr. No & $\begin{array}{c}\text { Name of } \\
\text { adders }\end{array}$ & $\begin{array}{c}\text { No. of } \\
\text { transistor }\end{array}$ & width & Delay(ns) & $\begin{array}{c}\text { Avg. power } \\
\text { (nw) }\end{array}$ & $\begin{array}{c}\text { Power delay } \\
\text { product (aj) }\end{array}$ & $\begin{array}{c}\text { Leakage } \\
\text { power (nw) }\end{array}$ \\
\hline 1. & CCMOS & 28 & $\mathrm{~W}^{*} 4$ & 5 & 13.99 & 69.95 & 2.127 \\
\hline 2. & B_V2 & 28 & $\mathrm{~W}^{*} 4$ & 5.91 & 18.74 & 110.75 & 2.422 \\
\hline 3. & B_V3 & 28 & $\mathrm{~W}^{*} 4$ & 5.94 & 13.46 & 79.95 & 2.132 \\
\hline
\end{tabular}

Table 3 represent comparison results of 32 bit Ripple Carry adders. All the circuit designs are simulated at $50 \mathrm{MHz}$ frequency. Proposed design has improvement in delay and power delay product.

Table 3. Result of 32 bit Ripple Carry adders

\begin{tabular}{|c|c|c|c|c|c|c|c|}
\hline \multirow{2}{*}{ Sr. no } & \multirow{2}{*}{ Parameters } & \multicolumn{3}{|c|}{$\begin{array}{r}\text { Mohammad Reza } \\
{[9]}\end{array}$} & \multicolumn{3}{|c|}{$\begin{array}{c}\text { Proposed design } \\
{[50 \mathrm{MHz}]}\end{array}$} \\
\hline & & CCMOS & $\begin{array}{c}\text { BRIDGE } \\
\text { STYLE } \\
\text { (B_V2) }\end{array}$ & $\begin{array}{c}\text { BRIDGE } \\
\text { STYLE } \\
\text { (B_V3) }\end{array}$ & CCMOS & $\begin{array}{c}\text { BRIDGE } \\
\text { STYLE } \\
\text { (B_V2) }\end{array}$ & $\begin{array}{c}\text { BRIDGE } \\
\text { STYLE } \\
\text { (B_V3) }\end{array}$ \\
\hline 1. & $\begin{array}{c}\text { Average } \\
\text { power }(\mu \mathrm{w})\end{array}$ & 0.190 & 0.063 & 0.063 & 1.554 & 1.654 & 1.480 \\
\hline 2. & Delay (ns) & 43.66 & 65.00 & 50.35 & 2.539 & 2.681 & 3.251 \\
\hline 3. & $\begin{array}{l}\text { Power delay } \\
\text { product }(\mathrm{fj})\end{array}$ & 8.320 & 4.112 & 3.189 & 3.946 & 4.434 & 4.811 \\
\hline 4. & $\begin{array}{c}\text { Leakage } \\
\text { power }(\mu \mathrm{w})\end{array}$ & - & - & - & 0.657 & 0.769 & 0.685 \\
\hline
\end{tabular}

\footnotetext{
1Jaspreetkaurp1@gmail.com
} 


\subsection{Simulation Result}

Simulation waveform of CCMOS is shown in fig 4. The input data $\mathrm{V}_{\mathrm{a}}, \mathrm{V}_{\mathrm{b}}, \mathrm{V}_{\mathrm{c}}$ and output sum and carry shown below:

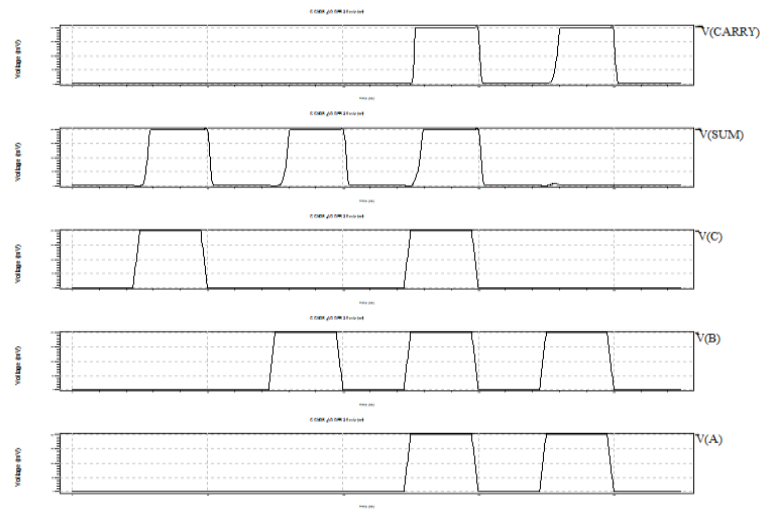

Figure 4. Output Waveform of CCMOS Simulation

\section{Conclusion}

The aim of this paper is reduce the power consumption. In this paper CCMOS design and bridge style adders are compared in sub-threshold region. Results show that significant improvements in power consumption, delay and power delay product with acceptable performance. All the adder circuits are designed at $20 \mathrm{MHz}$ and 50 $\mathrm{MHz}$ frequencies with $\mathrm{V}_{\mathrm{DD}}=200 \mathrm{mv}$. All adder designs are simulated at $32 \mathrm{~nm}$ technology.

In 1 bit Conventional CMOS adder, average power is improved by $99.66 \%$ and power delay product is improved by $95.17 \%$. In Bridge Style adder, average power is improved by $99.51 \%$ and power delay product is improved by $87.07 \%$.

In this paper circuits make use of 50MHZ frequency; then our result is improved. In 32 bit Conventional CMOS, delay is improved by $94.18 \%$ and power delay product is improved by $52.58 \%$. In Bridge style (B_V2) design, delay is improved by $95.87 \%$. In Bridge style (B_V3), delay improved by $93.54 \%$.

\section{References}

1. Neil H.E.Weste, David Harris and Ayan Banerjee "CMOS VLSI Design, a Circuit and System Perspective", Third Edition, Pearson Education, Inc., (2005).

2. Sung-Mo (Steve) Kang and Yusuf Leblebici, "CMOS Digital Integrated Circuits Analysis \& Design", Tata McGraw-Hill, (2005).

3. Mahdiar Ghadiry, Mahdieh Nadi and Abu Khari A'Ain, "DLPA: Discrepant Low PDP 8-Bit Adder", Journal of Circuits Syst. Signal Process, Vol. 32, Issue1, pp.1-14, (2013).

4. Deepak Garg, Mayank Kumar Rai, “ CMOS Based 1-Bit Full Adder Cell for Low-Power Delay Product", IJECCT 2012, Vol. 2 No.4, pp. 18-23, (2012).
5. Shiwani Singh ,Tripati Sharma ,K.G. Sharma, "9T Full Adder Design in Subthreshold Region", Hindwai Publication Corpoation VLSI Design Vol. (2012).

6. S.Wairya, Himanshu Pandey, R.K.Nagaria and S.Tiwari, Member, IEEE "Ultra Low Voltage High Speed 1-Bit CMOS Adder" IEEE , pp. 1-6,(2010).

7. Farshad Moradi, Dag T. Wisland, Tuan Vu Cao "1Bit Sub Threshold Full Adders in 65nm CMOS Technology"International conference on Microelectronics(IEEE),pp.268-271,(2008).

8. Xu Wang, Weifeng He, Zhigang Mao "New Robust 200mV Sub-threshold Full Adders" IEEE, pp.776778, (2010).

9. Mohammad Reza Bagheri,"Ultra Low Power Subthreshold Bridge Style Adder in Nanometer Technologies "Canadian Journal on Electrical Engineering Vol.2, No. 7,pp.294-299, July (2011).

10. Mariano Aguirre-Hernandez and Monico LinaresAranda, "CMOS Full Adder For Energy-Efficient Arithmetic Applications", IEEE Transaction on Very Large Scale Integration (VLSI) Systems, Vol. 19, No.4, pp.718-721,(2011).

11. .Vishal Sharma, Sanjay, "Low Power 1-BitCMOS Full-Adder Using Sub threshold Conduction Region", International Journal of Scientific \& Engineering Research vol. 2, June (2011).

12. Farshad Moradi, Dag.T.Wisland ,Hamid Mahmood, "Ultra Low Power Full Adder Topologies", Nanoelectronics Group , Department of informatics,University of Oslo,NO-0316 Oslo, NORWAY, pp.3158-3161,( 2009).

13. Keivan Navi and Omid Kavehei, "Low Power and High-Performance 1-Bit CMOS Full-Adder Cell" Journal of computers, vol. 3, no. 2,pp.48-54, February (2008).

14. 14. Jun Cheol Park and Vincent J. Mooney III, "Sleepy Stack Leakage Reduction", IEEE Transaction on Very Large Scale Integration (VLSI) Systems, Vol. No.11, pp. 1250-1263, Nov. (2006). 